\title{
2020: utopia e a distopia e a yout(uber)ização do trabalho docente
}

\author{
Prof. Dr. Hélio Arthur ReIS IRIgaray ${ }^{1}$ \\ ${ }^{1}$ Fundação Getulio Vargas (FGV EBAPE) / Escola Brasileira de AdMinistração Pública e de EMPRESAS, RIO dE JANEIRO - RJ, BRASIL
}

Quando o século XXI ainda era um futuro distante, foi retratado como um mundo utópico (como em Os Jetsons), no qual os seres humanos teriam uma jornada de trabalho reduzida e, principalmente, não executariam mais tarefas repetitivas e rudes - estas ficariam a cargo de máquinas inteligentes.

No entanto, houve quem descrevesse o futuro como uma distopia (como em Mad Max, e em tantos outros filmes), um cenário de guerras, epidemias e devastação ambiental.

Pois bem, chegamos a 2020 e, ao final deste ano tão surpreendente (para alguns; dado que para muitos cientistas este cenário de pandemia global já era há muito esperado), deparamo-nos com um mundo "dis-utópico", no qual os Jetsons vivem no mundo de Mad Max. Um lugar onde a utopia retratada no desenho animado supracitado (videochamadas, telemedicina, freezers, micro-ondas, carros voadores, robôs) anda lado a lado com desastres naturais de proporções apocalípticas, com um processo acelerado de desertificação e hordas de desesperados (refugiados, migrantes e excluídos) marchando sem rumo; além da infinidade de zumbis, seres sem capacidade cognitiva que questionam a ciência e se limitam a reproduzir fake news.

Esta colisão dos possíveis futuros, concebidos no século passado, concretizou-se em 2020, de tal forma que nosso maior desafio foi buscar um sentido para nossa própria vida, o que nos permitiria, na concepção de Jung (2020-1972), enfrentar qualquer coisa.

De fato, dar sentido à própria vida é a única alternativa para suportarmos a dor pelo sofrimento alheio, a perda de familiares, amigos e de milhões de seres humanos, e enfrentarmos a solidão decorrente do distanciamento social, bem como a reconfiguração abrupta do mundo do trabalho.

Nestes últimos meses, testemunhamos o agravamento da taxa de desemprego, além da precarização do trabalho em si, ou, nas palavras de Antunes (2001, p. 6), "o desmonte dos direitos trabalhistas". O sequestro das garantias formais dos trabalhadores, a redução unilateral e inquestionável de suas jornadas de trabalho e salários, a falta de equipamentos de segurança para garantir a sua saúde e a sua integridade física desvelaram a lógica mais perversa do capitalismo (MACHADO, GIONGO e MENDES, 2016).

Muitos destes foram reduzidos a camelôs, a trabalhadores temporários, a PJs (pessoas jurídicas), que, não raramente, são descritos - e até glorificados - como empreendedores: são os tempos da uberização do trabalho (FONTES, 2017). “A realidade dos docentes não foi diferente".

Numa entrevista televisionada no período pré-eleitoral, um político asseverou que estava na hora de os professores voltarem ao trabalho. Mas quando foi que deixamos de trabalhar?

Em tempo recorde, valendo-nos de aparatos tecnológicos e mídias digitais, redesenhamos nossas aulas e atividades. Trabalhamos mais horas do que antes seria necessário e ainda fomos cobrados para despertar o interesse e promover o engajamento dos alunos. Vivemos a yout(uber)ização das atividades docentes.

Nas aulas, tornamo-nos responsáveis por todos os alunos manterem a câmara aberta, por participarem; devemos transmitir conteúdo, mas, ao mesmo tempo, não podemos estender nossas falas sob pena de entediarmos a audiência. Somos mestres que devem ensinar entretendo. 
A yout(uber)ização evidencia uma relação facilmente obscurecida entre desenvolvimento tecnológico e precarização do trabalho, na medida em que potencializa sofrimentos físicos e psíquicos dos docentes.

Ansiosos e angustiados, fomos obrigados a desenvolver novas competências. Passamos a enfrentar novas fontes de estresse (além das já conhecidas): a demanda de nos reinventarmos em curto espaço de tempo (redesenhar nossas aulas e dinâmicas), a cronometragem milimétrica de nossas aulas, a ansiedade porque algo pode falhar (a internet cair, a luz faltar), a criação de vínculos com os alunos em um ambiente virtual; além das dores físicas por longas horas no computador e dos custos financeiros com os quais passamos a arcar (internet, eletricidade).

Apesar de todos estes desafios, encontramos tempo para pesquisar e produzir artigos relevantes, como estes que compõem nossa última edição do ano.

O primeiro, "Perspectivas de carreira de jovens do ensino médio de escolas públicas: transgressão ou reprodução das condições sociais?", escrito por Heliani Berlato, Luciano Mendes e Danilo Andretta, analisa as perspectivas de carreiras dos jovens do ensino médio público, no que tange aos aspectos sociais, familiares, educacionais e culturais. Para tanto, discutiu-se a carreira por duas perspectivas: o sucesso e as indecisões inerentes a ela.

Marcia de Freitas Duarte, em “"The One Best Way?” Repensando a difusão do management e seus impactos em decisões na carreira acadêmica em Administração", propõe que repensemos os aspectos relacionados à origem e à difusão do ensino e da pesquisa na área de Administração. Assim, por meio de uma narrativa confessional, são apresentados o processo de desenvolvimento e legitimação do ensino e pesquisa em Administração, tendo como base a literatura que trata do americanismo e do pós-colonialismo.

Em "Mais uma vez o conceito de gestão social", Fernando Guilherme Tenório e Edgilson Tavares de Araújo revisitam esse conceito, que talvez seja uma quimera, um sonho que pode não se realizar, dadas as condições de "temperatura e pressão" sob as quais vivemos na contemporaneidade.

Alex Fernando Borges e Alessandro Gomes Enoque reveem a literatura do empreendedorismo publicada em língua francesa em "Pesquisa em empreendedorismo: a produção científica francófona em perspectiva". Os textos foram analisados e categorizados com base na distribuição dos artigos entre os periódicos, na distribuição anual, nos principais temas de pesquisa, no tipo de abordagem, nas escolhas metodológicas e nos principais autores do campo. Os resultados indicaram predominância de temáticas específicas na produção francófona, como: fomento ao empreendedorismo, intraempreendedorismo, processo empreendedor e oportunidades, empreendedorismo feminino, finanças, educação empreendedora, perfil e comportamento empreendedor, intenção empreendedora, motivações ao empreendedorismo e empreendedorismo social.

"Pandemia do COVID-19 e mudanças no Estado: surgirá uma nova administração pública em resposta essas mudanças?", escrito por Josep Pont Vidal, discute as consequências dos impactos causados pela pandemia do COVID-19 na administração pública, bem como sua autonomia e configuração.

Em "Análise de viabilidade econômica financeira do uso de vinhaça para geração de eletricidade no Brasil", Geraldo Jose Ferraresi de Araujo e Sonia Valle Walter Borges de Oliveira analisam a viabilidade econômica do uso de vinhaça para geração de eletricidade. Como objetivo específico, os autores identificam a faixa de preço viável do MWh nos ambientes de energia livres e regulados e a capacidade produtiva das plantas para esse tipo de investimento.

Lua Syrma Zaniah Santos, Valéria Gama Fully Bressan, Vilmar Rodrigues Moreira e Romeu Eugênio de Lima examinam a relação entre o risco de crédito e a eficiência das cooperativas de crédito brasileiras no período de 2008 a 2017, em "Risco de crédito e eficiência técnica nas cooperativas de crédito brasileiras".

Em "Parcerias público-privadas de saúde e mobilidade urbana no Estado da Bahia: atual conjuntura, projetos e principais agentes envolvidos", Maina Pirajá Silva, Silvana Sá de Carvalho e Mariana de Oliveira Santana identificam as parcerias público-privadas (PPPs) existentes no Estado da Bahia, avaliam e comparam, por meio de estudos de caso das parcerias de saúde e mobilidade urbana, a efetividade destas mediante o exame da estruturação dos projetos, implementação e funcionamento das concessões, bem como ponderam sobre os agentes públicos e privados envolvidos e suas articulações.

"O Conselho Tutelar e as políticas públicas para crianças e adolescentes", de Hemerson Luiz Pase, Gabriele Padillha Cunha, Marcia Leite Borges e Ana Paula Dupuy Patella, traz uma análise sobre o papel do Conselho Tutelar na consolidação da proteção e da fiscalização dos direitos de crianças e adolescentes no município de Pelotas. 
Em "Desafios da coordenação federativa da Política de Assistência Social: o papel dos estados no financiamento", Isabela de Vasconcelos Teixeira e Bruno Lazzarotti Diniz Costa analisam o grau, a variação e os determinantes da corresponsabilidade do financiamento da política de assistência social pelos entes estaduais, verificando a contribuição dos mecanismos de coordenação e indução federativa, apontados por vários autores como fator de sucesso.

Fabiana Tock, Eduardo José Grin e Lauro Gonzalez buscam explicar como a combinação entre as características institucionais do SUAS e as condições estruturais, institucionais e políticas presentes regulam ou possibilitam a criação de capacidades estatais. Os resultados de "Os estados e o Sistema Único de Assistência Social: construção de capacidades estatais nos governos do Maranhão e de São Paulo" apontaram que tais condições foram determinantes na construção de capacidades e, sobretudo, informam a respeito do papel assumido pelo governo do estado no SUAS.

Em "Comunidade Noiva do Cordeiro: contribuições por meio de elementos de um sistema baseado em uma economia substantiva", Luiz Paulo Rigueira de Morais, Wescley Silva Xavier e Daniel Calbino Pinheiro investigaram como ocorreram a formação e a interação de um sistema econômico alternativo na comunidade Noiva do Cordeiro-MG com as dinâmicas da economia mercantil.

Gustavo Henrique Carvalho de Castro e Marcus Vinicius Soares Siqueira, em “"Vão achar que é uma piada, mas, para nós, não!": discursos de resistência em clubes brasileiros de futebol gay", discutem a discriminação contra homossexuais, perpetrada pela injúria homofóbica, atos performativos de fala que silenciam e afastam indivíduos gays, reforçando o culto à masculinidade hegemônica.

Em “Mulheres na política: emoções e desafios em dinâmicas institucionais complexas", Camilla Fernandes, Mariane Lemos Lourenço, Samantha Frohlich, Diogo Espejo da Silva e Flávia Obara Kai exploram o papel das emoções nas dinâmicas institucionais, especialmente quanto à participação política das mulheres nas eleições brasileiras de 2018.

Por fim, "Do sagrado ao profano: aproximações entre a teologia cristã e a administração", de Aline Van Neutgem e Eloise Helena Livramento Dellagnelo, apresenta uma aproximação entre a administração e a teologia cristã.

Tenham uma boa leitura!

Prof. Dr. Hélio Arthur Reis Irigaray

Editor-chefe 


\section{REFERÊNCIAS}

ABÍLIO, L. C. A 'uberização' e as encruzilhadas do mundo do trabalho. IHU On-Line - Revista do Instituto Humanitas Unisinos, ano 15, n. 503, p. 2, abr. 2017. Disponível em: <http://www.ihuonline.unisinos. br/media/pdf/IHUOnlineEdicao503.pdf>. Acesso em: 03 dez. 2019.

ANTUNES, R. Os sentidos do trabalho: ensaio sobre a afirmação e negação do trabalho. 6. reimp. São Paulo: Boitempo Editorial, 2003.

FONTES, V. Capitalismo em tempos de uberização: do emprego ao trabalho. Marx e o Marxismo-Revista do NIEP-Marx, v. 5, n. 8, p. 45-67, 2017.
JUNG, C. G. Collected works of C. G. Jung. Volume 7: Two Essays in Analytical Psychology. 2. ed. Edição Kindle. Princeton: Princeton University Press, 2020-1972.

MACHADO, F. K. S.; GIONGO, C. R.; MENDES, J. M. R. Terceirização e precarização do trabalho: uma questão de sofrimento social. Revista Psicologia Política, v. 16, n. 36, p. 227-240, 2016. 